\title{
FAILURE EVALUATION METHOD FOR A SLOPE MONITORING SYSTEM
}

\author{
H.K. KIM \& C.Y. CHOI \\ Advanced Railroad Civil Engineering Division, Korea Railroad Research Institute, Korea
}

\begin{abstract}
Recently safety of Korean railway lines has been threatened by typhoon and heavy rainfall due to global warming and representative rainfall induced risks are landslides, slope failure, debris flow, fallen rocks etc. Risks of slope failures are evaluated by deformation of ground surface and underground movements. But many bore holes and sensors must be equipped in the ground for detecting of deformation of ground movements. Furthermore, it is not easy to confirm slope failure immediately and needs much time for post-processing of various data. Only one or very specific sections could be monitored for limited area due to budget. A multipurpose sensor is developed for overcoming these problems by use of data from inclinometer installed on the ground surface. Motions at a point of ground surface could be simply divided into rotation and linear movements and they might be representative sensor signals. In this study, failure types, slip surface, failed mass and failure direction could be recognized by use of these characteristics; sensor data and an algorithm to detect these movements are suggested. Failure shapes such as circular and planar failure are estimated by combination of simplified ground movements. For determination of a two-dimensional (2D) slip surface, 3D coordinates of a main slope profile and all sensor locations should be defined. Then specific equation to estimate slip surface is selected. After selection of starting and ending point of slip surface, the tangent value of a slip surface could be calculated from each sensor. 2D slip surface is calculated by combination of sensor location, the equation, tangent values and each ending point. 3D failed soil mass is also estimated from various 2D slip surfaces. By use of centre of mass, we could get movement direction of failed soil mass. An examination of this algorithm has been executed in a railway slope. Consequently, it is possible to estimate slip surface and failed soil mass using data from ground surface.

Keywords: algorithm, detection, monitoring, sensors, slope failure.
\end{abstract}

\section{INTRODUCTION}

In order to monitor the deformation of slopes along railroad and highway, it is necessary to measure deformation (surface displacement and inclination) of ground surface and ground deformation (ground gradient, pore water pressure, volumetric water content and groundwater level). To determine the status of slope collapses, it is necessary to evaluate the deformation of profiles in the ground and movements of ground surfaces as well. The method of estimating the slip surface using the deformation information of the ground (prediction of the scale of collapse) is predicted by using the inflection point of the ground inclination meter [1-3]. Also it has been progressed by using three-dimensional (3D) survey or changes in vector's movements of pre-set coordinates based on the ground surface information $[4,5]$. However, a large number of bore holes should be installed on the slope to embed the sensor. Because the measurement is carried out for the critical section to reduce the cost, it is difficult to predict the overall activity of a slope. In case of 3D survey, it takes a long time to postprocess, and it is not possible to grasp the instability of the slope immediately due to changes in natural conditions such as rainfall. Also, sometimes conventional monitoring system using bore holes could not detect deep slope failures by location of slip surface. It is difficult to estimate overall failure mass and failure direction of a slope because sensors are installed and monitored for limited area. Because estimating method by in situ investigation and bore-hole test is carried out after slope failure, it is difficult to ensure safety at the site and take time [6]. 
In this research, evaluation method for detection of a slope failure, failure type, failure slip surface, failure magnitude and direction is developed using various data such as sensor locations, directions and inclination from multi-measuring points by sensors. It is expected that slope monitoring system will be further improved by using this method.

\section{TEST FOR CHARACTERISTICS OF SENSOR DATA AT SLOPE FAILURE}

In this study, a sliding table was used to construct a model slope in order to grasp the motion pattern generated on the slope. The generated signals were analysed in response to the slope change. Movement of the sensor when sliding was classified into sliding and slope angle (Fig. 1). In addition, laboratory tests were carried out to evaluate the dangerous conditions including slope failure using information on the ground surface accompanying slope failure (Figs 2 and 3). Material properties are shown in Table 1.

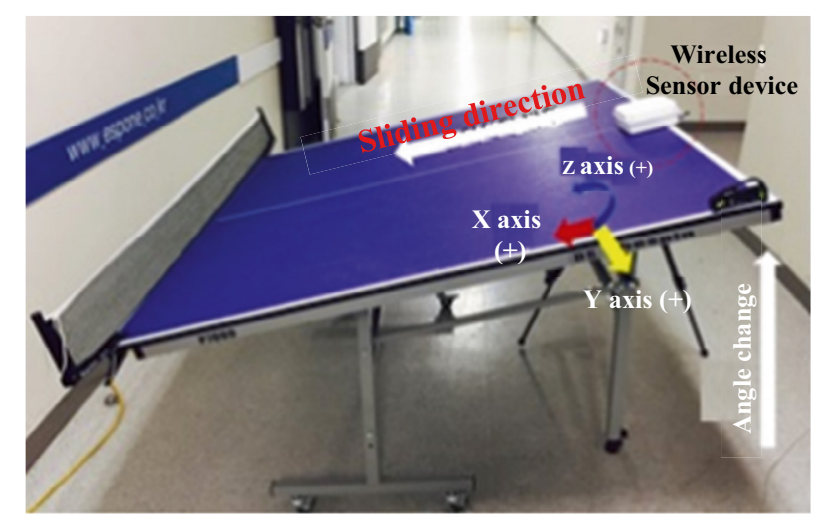

Figure 1: Model slope for simulation of sensor movements.

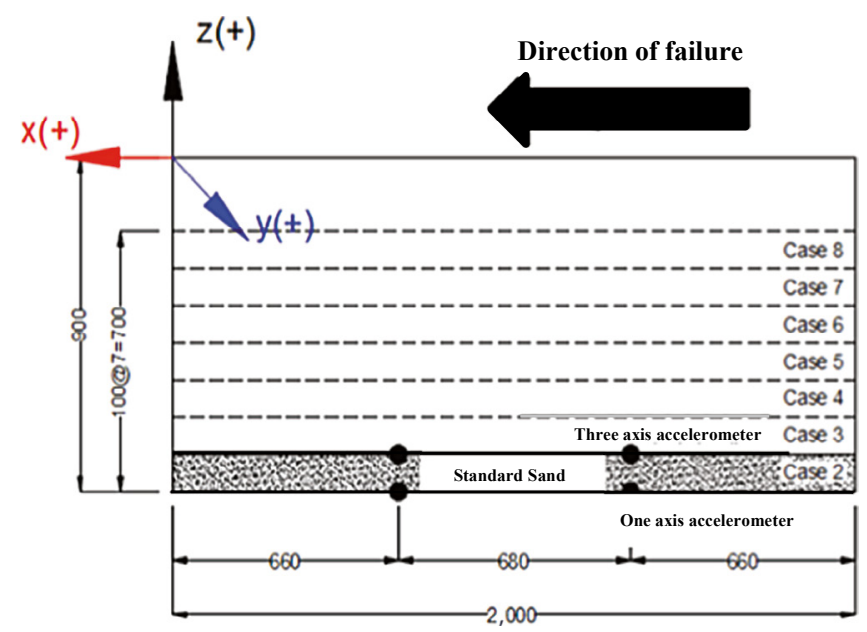

Figure 2: Dimension of a soil tank. 


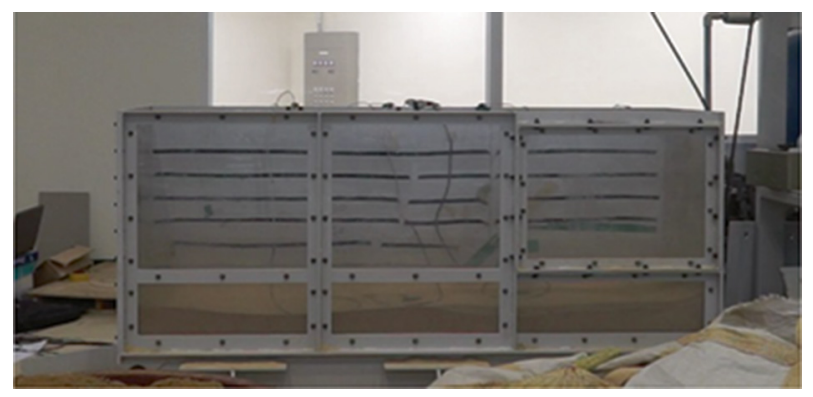

Figure 3: A soil tank.

Table 1: Material properties

\begin{tabular}{llllll}
\hline $\begin{array}{l}\text { Soil } \\
\begin{array}{l}\text { Classification } \\
\text { (USCS) }\end{array}\end{array}$ & $\begin{array}{l}\text { Specific } \\
\text { gravity }\end{array}$ & $\begin{array}{l}\text { Minimum Dry } \\
\text { Unit Weight } \\
\left(\mathrm{t} / \mathrm{m}^{3}\right)\end{array}$ & $\begin{array}{l}\text { Maximum Dry } \\
\text { Unit Weight } \\
\left(\mathrm{t} / \mathrm{m}^{3}\right)\end{array}$ & $\begin{array}{l}\text { Internal } \\
\text { friction } \\
\text { angle }\left(^{\circ}\right)\end{array}$ & $\begin{array}{l}\text { Uniformity } \\
\text { Coefficient }\end{array}$ \\
\hline SP & 2.65 & 1.33 & 1.66 & 37.8 & 1.68 \\
\hline
\end{tabular}

\section{DEVELOPMENT OF EVALUATION METHOD OF COLLAPSE USING SLOPE DEFORMATION INFORMATION}

By use of properties of slope failures at ground surface simulated in laboratory test and theoretical equations, evaluating method could be developed. Slope failures are divided into circular failure, toppling, wedge failure, planar failure and combined failure. If information from sensor is used appropriately, occurrence of these breakdowns can be evaluated.

A method to evaluate slope failure and slip surface includes four steps such as (1) slope failure itself, (2) shape of failure, (3) estimation of slip surface, (4) collapsed soil mass and failure direction using deformation data from several sensors installed in slope surface.

\subsection{Detection of slope failure}

Recognition of slope failure is predicted from deformation data of various sensors on the ground as shown in Fig. 4a. The sensors installed in Sections I and V do not change, but some of the sensors or all of them installed in Sections II, III and IV made some change in

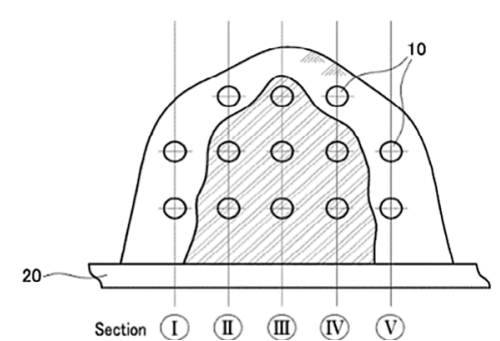

(a) Multiple sensors installed slip surface

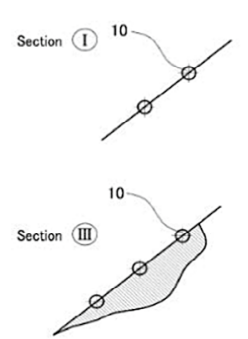

(b) Behavior of each section by sensor location

Figure 4: Multiple sensors installed in a slip surface. 
acceleration and angle. Slope failure condition could be detected by use of these information (Fig. 4b).

Accelerometer and the change of each displacement do not change in the normal range when the sensor moves on a predetermined slope. But when a sensor separates or fails from a slope, their data are diverged. Though they are meaningless data, this information can be used to confirm the occurrence of a slope failure (Fig. 5).

\subsection{Evaluation of collapse mode}

The motion of the point located on the slope can be divided into slip, rotation and behaviour at failure. Slip is represented by plane failure of a slope, and rotation is defined as circular failure. The behaviour at slope failure is judged by diverged sensor data such as slope failure, debris flow and fallen rocks. In this way, the destructive pattern of a slope can be determined by rotational motion, linear motion and divergence (Fig. 6).

It is possible to confirm simple movement using a sensor data installed on ground surface such as acceleration and rotation angle. Macroscopic collapse shapes (circular failure, planar failure and combined failure) are estimated by calculation of movement at each sensor point.

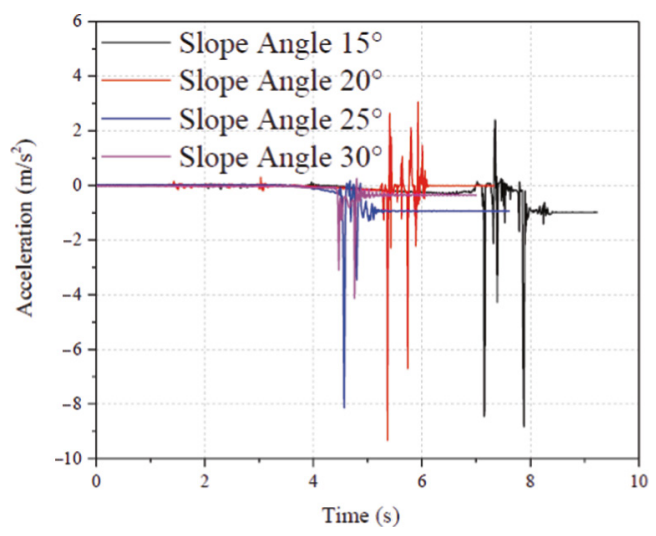

(a) Variation of acceleration of a sensor

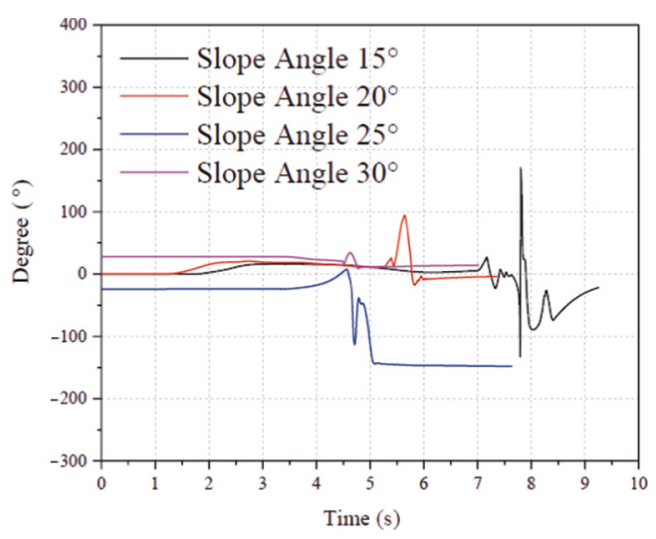

(b) Variation of inclination of a sensor

Figure 5: Movement data of each sensor as its sliding. 


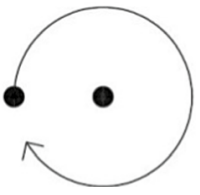

(a) Rotation

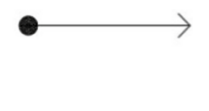

(b) Linear movement

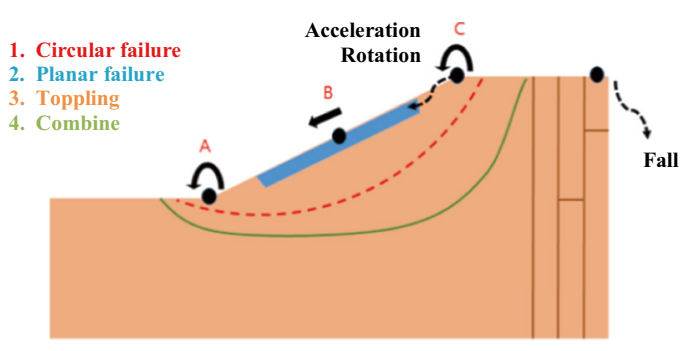

(c) Movement

Figure 6: Simplified ground movement.

For example, if information obtained from A, B, C sensors are all rotation, it means circular failure. However, if $\mathrm{A}$ and $\mathrm{C}$ are in rotation and $\mathrm{B}$ did not show any change, it defines planar failure. It is defined as a combined failure when A, B, C sensors show rotation, linear and combined movements. In case of falling or collapsing, it is possible to judge the form of collapse by data divergence (Fig. 6).

This concept is compared with the results of laboratory test and to evaluate the collapse modes. The evaluation of the collapse mode is executed based on the fact that it is possible to distinguish the sliding, rolling (rotation) and movement at failure on a slope according to variation of acceleration and rotation angle measured by the sensor.

Figure 5 shows the change of the acceleration and the rotation angle due to the movement of the sensor installed on a slope surface by change of the inclination of a slope. No changes are generated with respect to the sliding motion of the slope. Slip motion can be judged by using this characteristics.

As shown in Fig. 7, when the acceleration and the rotation increase in proportion to the change of the angle of a slope, it is judged to rotate deformation, that is, circular failure. However, when the sensor is separated or broken down from the ground, the data will diverge in Fig. 8. When there is a sudden acceleration in a sensor and the data diverge as well, there is a dynamic collapse such as fallen rocks, debris flow etc. In particular, these characteristics of data are used in protection structure for debris flow and fallen rocks and it is possible to detect the occurrence of disaster.

\subsection{Activity surface estimation}

To establish a method for predicting failure surface of a slope using variation of angle at ground surface, it is assumed that a block moves as follows (Figs 9 and 10).

(1) Soil mass is separated by crack and fault by failure

(2) Moving soil mass is like a rigid body: Deformation $<<<$ Movement

(3) The height and angle of slip surface and upper ground surface are same at each block

(4) Deformation (angle, vector etc.) data at slip surface are the same value at ground surface

(5) Angle of variation of ground surface by ground deformation is parallel to angle of slip surface

(6) Location of start and end of slip surface defines as the location of upper and lower crack 


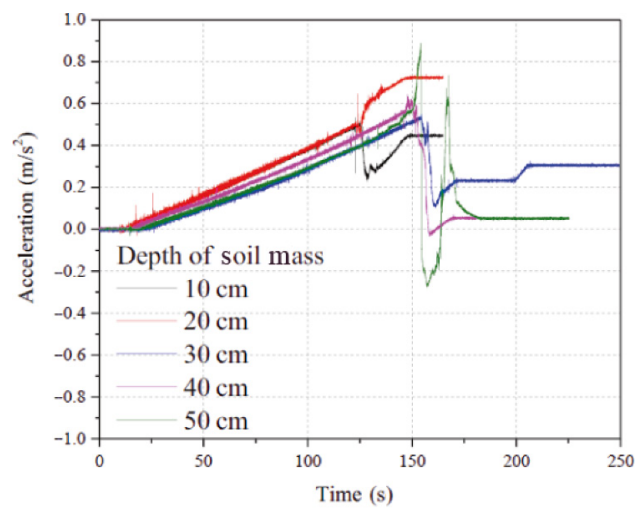

(a) Variation of acceleration of a sensor

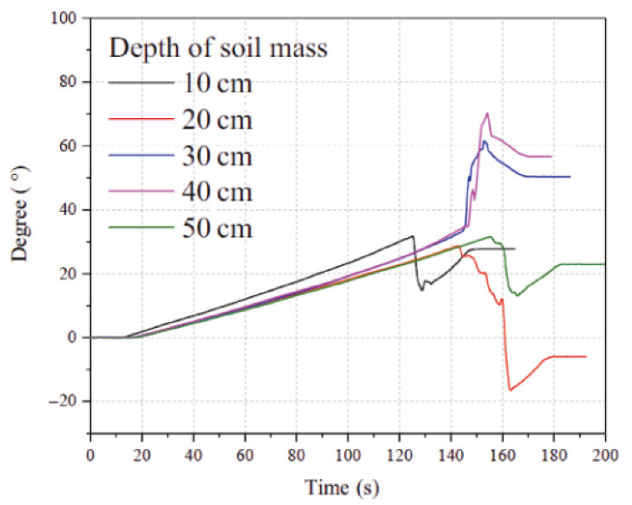

(b) Variation of inclination of a sensor

Figure 7: Sensor data of each sensor as its rotating.

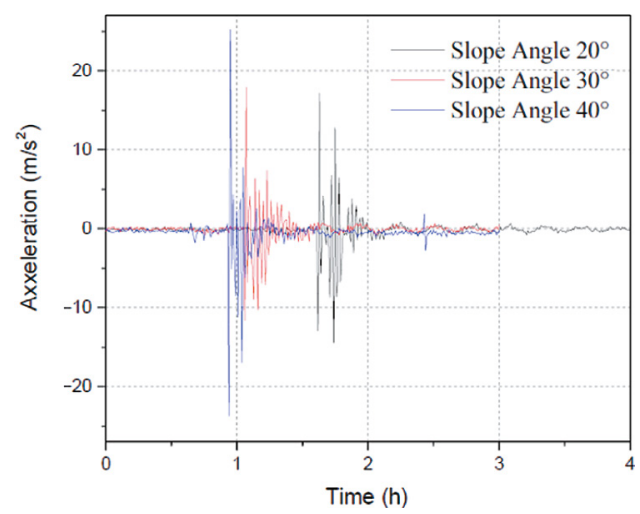

Figure 8: Sensor data characteristics with a slope failure (collapse). 


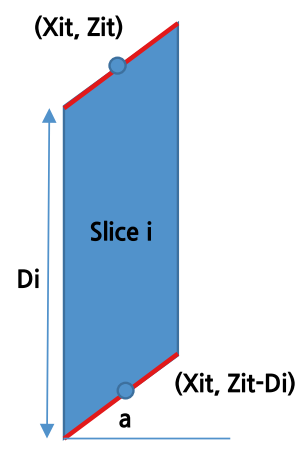

Figure 9: A slice (i) of a slip surface.

Fixed sensor

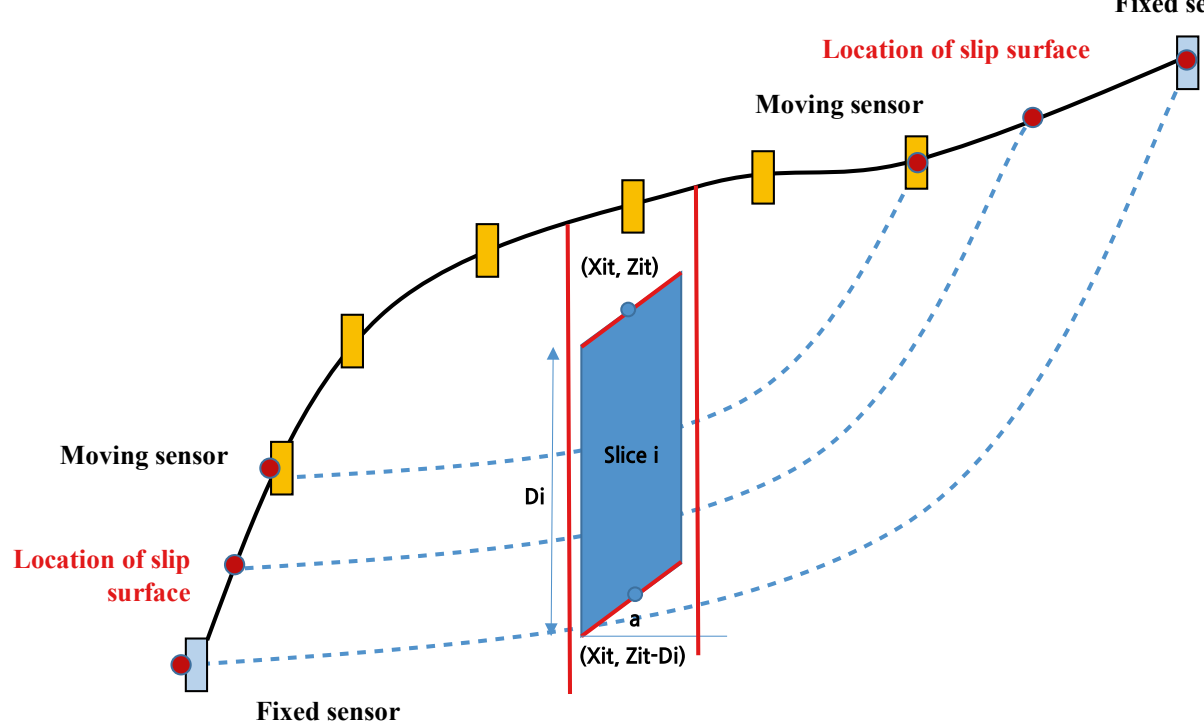

Figure 10: Start and end point for predicting for slip surface.

At first, location of starting and ending point is determined for evaluating slip surface. And then any equation $f\left(z_{i}\right)$ is defined to estimate slip surface. $f\left(z_{i}\right)$ could be a simple (or quadratic, cubic, etc.) equation. Gradient of tangent line $\tan _{i}\left(\theta_{i}\right)$ is calculated at coordinate $x_{i}$ based on deformation data from various sensors on ground, where $\theta_{i}$ is variation of slope angle. It must be the same value with deferential equation at a point; so, $f^{\prime}\left(z_{i}\right)=\tan _{i}\left(\theta_{i}\right)$. Thus, by calculating the gradient of tangent line at $x_{i}$, we can obtain the correct solution and optimum solution of the coefficient of equation $\left(a_{i}, b_{i}, c_{i}\right.$, etc.). Finally slip (failure) surface could be determined. For a quadratic equation, starting and ending points of the slip surface are defined as $\left(x_{\text {inidown }}, z_{\text {inidown }}\right),\left(x_{\text {iniup }}, z_{\text {iniup }}\right)$ and the equation is generally expressed as $Z_{2 i}=a_{2 i} \times x_{2 i}^{2}+b_{2 i} \times x_{2 i}+c_{2 i}$. Several slip surfaces could be obtained by selecting the 


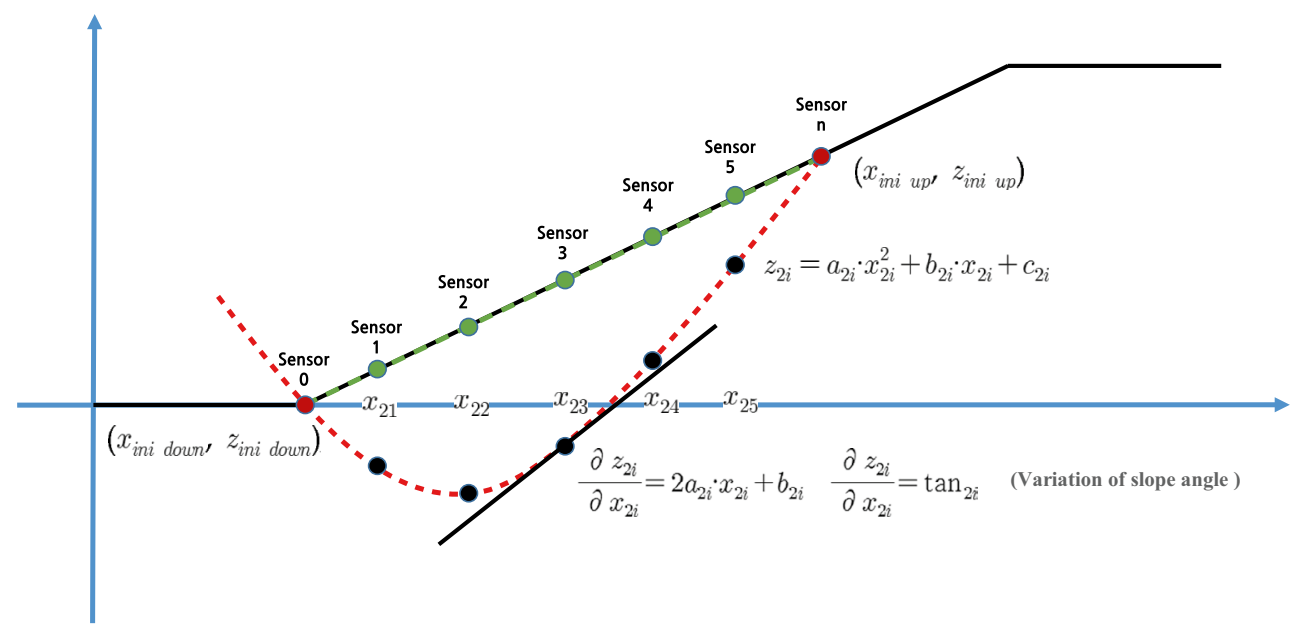

Figure 11: Calculation of tangent slope of each sensor.

location of starting and ending points. The gradient of slip surface might be calculated using measured inclination data from each sensor.

Gradient of tangent line at each point (deferential value): $\frac{\partial z_{z i}}{\partial x_{z i}}=\tan _{2 i}$ (variation of slope
angle) $x_{i}$ value at each point is a known value: $x_{2 i}\left(x_{21}, x_{22}, x_{23}, x_{24}, x_{25}\right)$

Using known point from Eqn (1) and (2) and gradient of tangent line of quadratic equation, slip surface could be calculated.

Equation of slip surface: $x_{2 i}=a_{2 i} \times x_{2 i}^{2}+b_{2 i} \times x_{2 i}+c_{2 i}$

Known point: $\left(x_{\text {inidown },} z_{\text {inidown }}\right),\left(x_{\text {iniup }}, z_{\text {iniup }}\right)$, By applying $\frac{\partial z_{z i}}{\partial x_{z i}}=2 a_{2 i} \times x_{2 i}+b_{2 i}$ and $\frac{\partial z_{z i}}{\partial x_{z i}}=\tan _{2 i}$ (variation of slope angle), calculate gradi-
ent at $x_{2 i}$

$$
\begin{aligned}
& x_{21}: \tan _{2 i}\left(\theta_{21}\right)=2 a_{2 i} \times x_{21}+b_{2 i} \\
& x_{22}: \tan _{2 i}\left(\theta_{22}\right)=2 a_{2 i} \times x_{22}+b_{2 i} \\
& x_{23}: \tan _{2 i}\left(\theta_{23}\right)=2 a_{2 i} \times x_{23}+b_{2 i} \\
& \ldots \\
& x_{2 n}: \tan _{2 i}\left(\theta_{2 n}\right)=2 a_{2 i} \times x_{2 n}+b_{2 i}
\end{aligned}
$$

Calculating $a_{2 i}, b_{2 i}, c_{2 i}$ : a correct solution or optimum solution. 
Failure (slip) surface can be easily estimated by use of this method for each section (Fig. 11). In this study, second-order equation as an example is explained and it is possible to apply the method of estimating slip surface, such as high-order polynomials.

\subsection{Estimation of collapsed soil mass and failure direction}

Using the method of 3.3, it is possible to estimate the two-dimensional slip surface of a slope on which various sensors are installed. The magnitude of the two-dimensional collapse can be calculated from information obtained from one cross-section, 2D. Then, combination of the 2D slip surfaces can be used to calculate the magnitude of 3D collapsed soil mass. It is possible to estimate 3D collapse magnitude $\left(\mathrm{m}^{3}\right)$ by calculating and combining a plurality of two-dimensional areas using 2D slip surfaces. And direction or path of slope failure could be identified by using the centre of gravity of the volume.

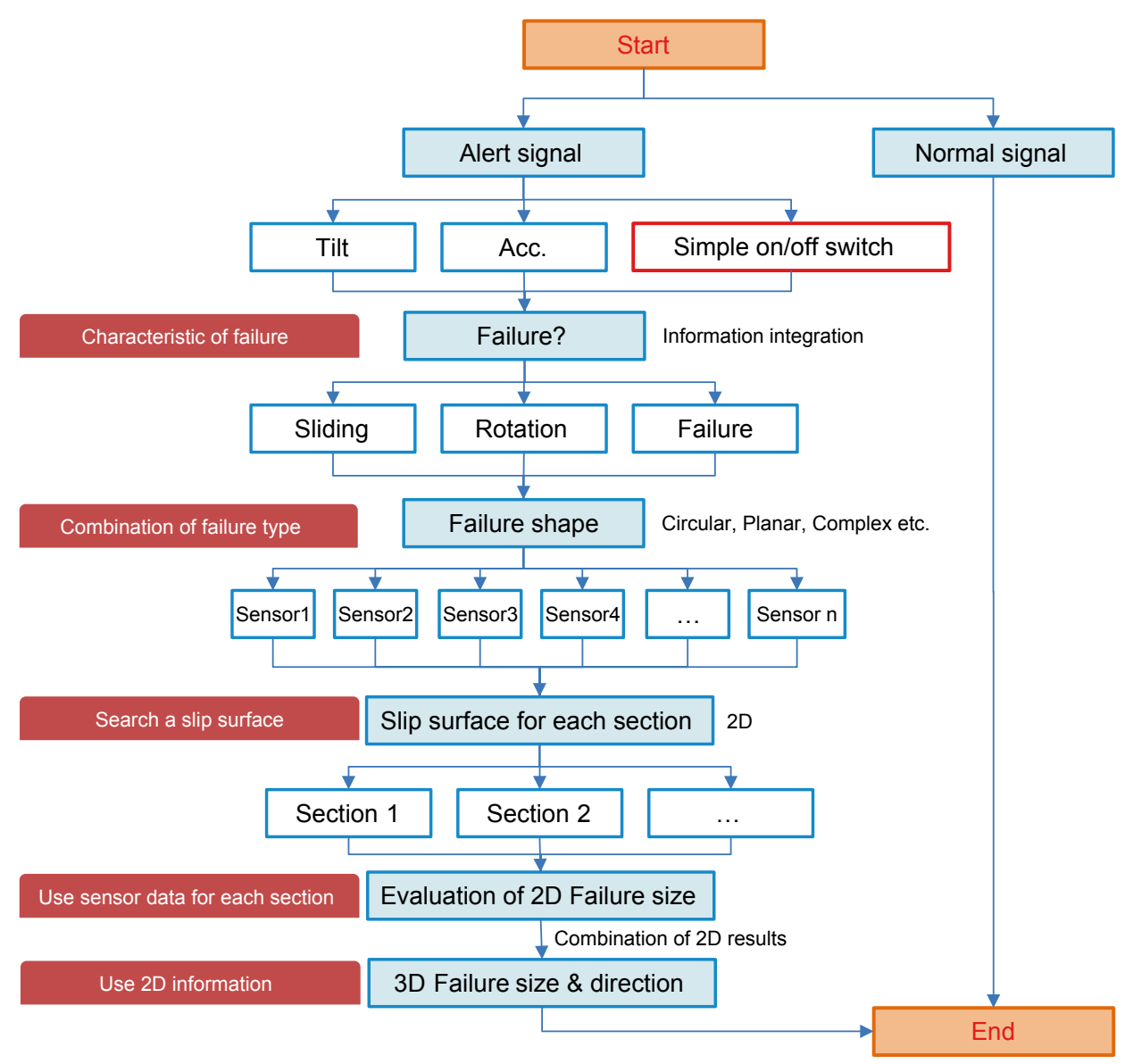

Figure 12: Algorithm for slope failures. 


\section{DEVELOPMENT OF A SLIP SURFACE EVALUATION PROGRAM USING VARIATION DATA OF GROUND SURFACE}

A program to monitor slope collapse, failure type, estimation of slip surfaces, destructive scale and estimation of failure direction was developed in this study (Fig. 12).

(1) (Confirmation of collapse occurrence) When abnormal information is obtained from the sensor, whether a slope has been failed should be confirmed by rotation and acceleration data

(2) (Failure type) Sensor data are combined to evaluate slope deformation such as slip, rotation and collapse

(3) (2D slip surface evaluation) Estimate 2D slip surface by using the sensor data installed at each cross-section. The size of the three-dimensional collapsed sediment is evaluated using 2D slip surface determined for each cross-section of a slope

(4) (Determination of direction or path of slope failure) The direction of collapse is evaluated by using the centre of gravity and inclination of failed soil mass.

Spreadsheet-based program is developed using the above algorithm to predict slope failure surface. In this study, equations of circular curve and parabolic curve are used as an example. At first, dimension of a slope and locations of installed sensors should be defined in

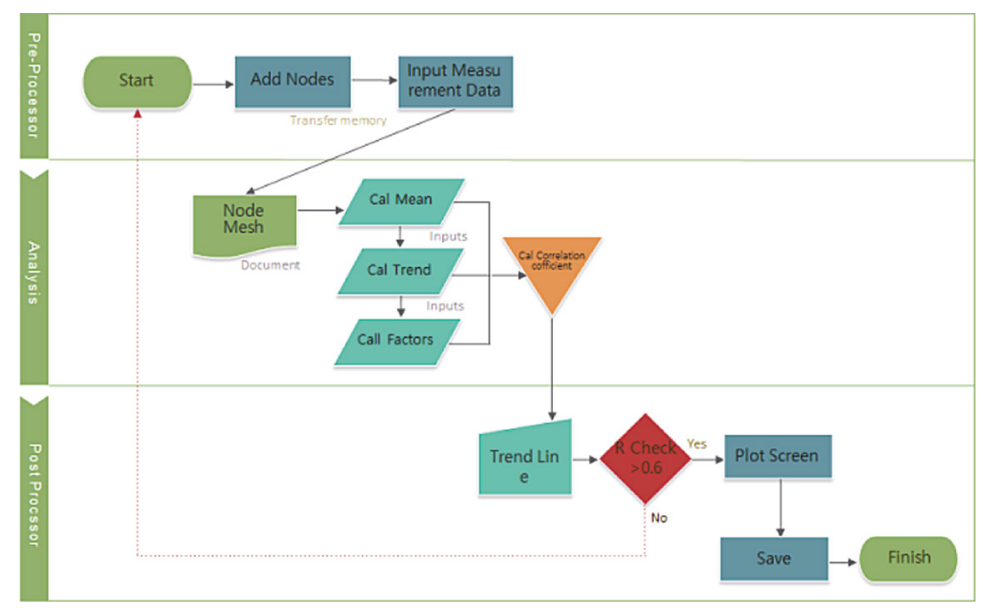

Figure 13: A flow chart of failure surface evaluation program based on quadratic function.

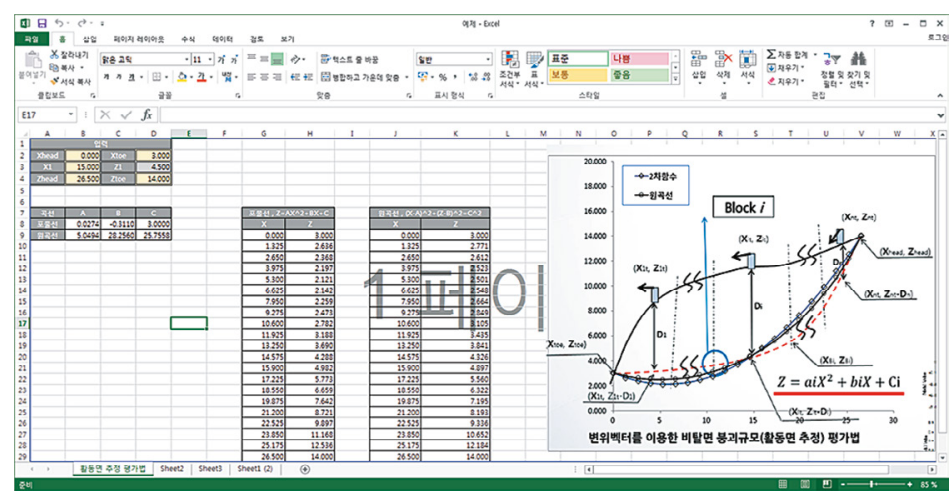

Figure 14: An example of a program. 


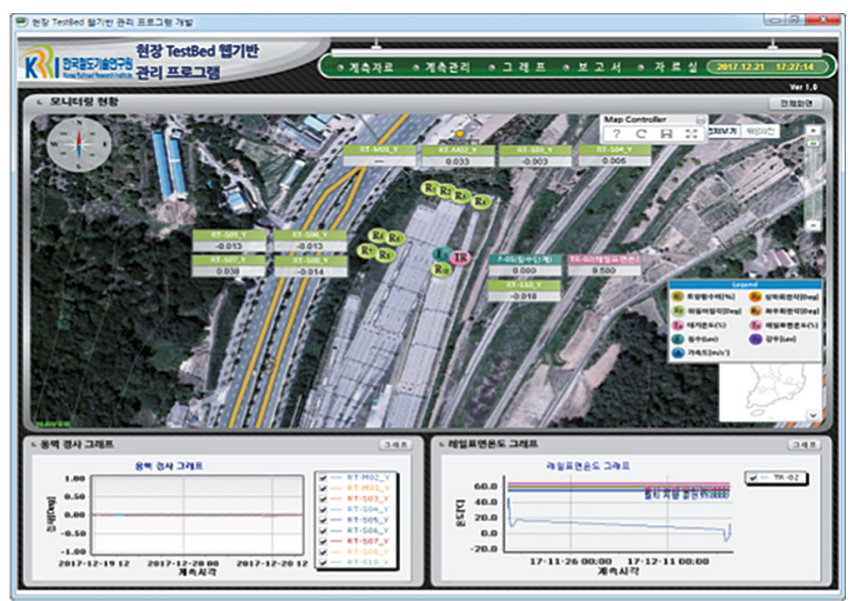

Figure 15: Test bed in Daejun Metro Lines.
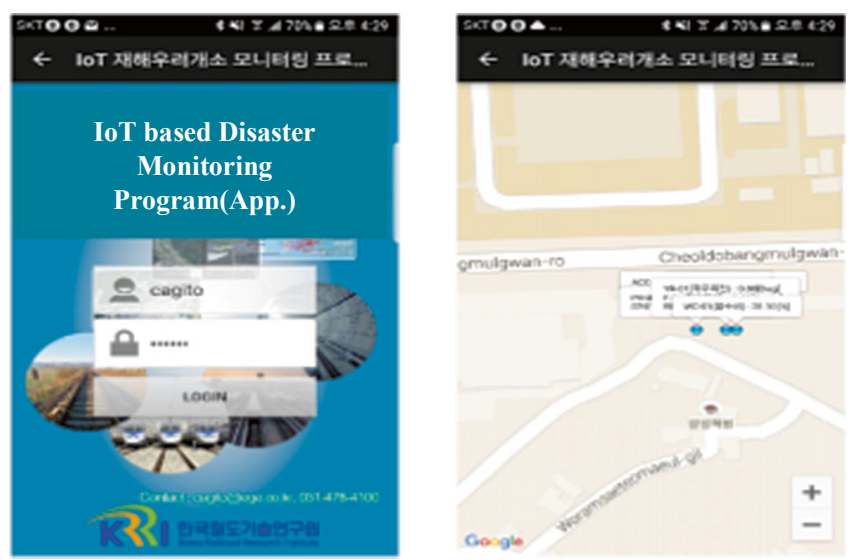

Figure 16: Smartphone application.

3D coordinates. And data from various sensors acquired in real time. Finally, slip surface is searched by using these data (Fig. 13). Figure 14 shows an example of operating this algorithm.

This program is equipped in Test Bed monitoring system in Daejeon Metropolitan Rapid Transit Corporation. Slope failure data can be confirmed in real time by web page and smartphone application (Figs 15 and 16).

\section{CONCLUSIONS}

A method to evaluate slope failure, failure pattern, slip surface, collapsed soil mass and direction is developed using location, direction and angle data from sensors installed in ground surface. Conclusions in this study are as follows: 
(1) It is possible to identify the type of slope failure (circular, planar, toppling, etc.) using ground surface information (acceleration, rotation angle, etc.) and confirm whether collapse will occur.

(2) It is possible to confirm the size of ground collapse through the estimation of slip surface using change of inclination of ground surface, and to examine the direction of collapse integrating 2D slip surfaces.

(3) Emergency action plan could be possible based on various types of sensor data installed on a slope to estimate the scale of slope failure and its occurrence

Slip surface of the collapse using the slope data of the ground surface could be estimate and it will help to arrange equipment and manpower for rapid restoration works by collapse scale.

\section{ACKNOWLEDGEMENTS}

This research was supported by the Korea Agency for Infrastructure Technology Advancement under the Ministry of Land, Infrastructure and Transport of the Korean government (Project Number: 17SCIP-B108153-03).

\section{REFERENCES}

[1] Shin-ichi, K., Kazunori, F., Naoto, T. \& Akira, T., Examination of applicability of slip plane estimation program. Proceedings of the 46th Japan Landslide Society Research Presentation, Yokkaichi City Cultural Center, Japan, pp. 323-326, 2007.

[2] Skurai, H., Adachi, K., et al., Slope stability evaluation using measurement results. Soil and Foundation, 49(7), pp. 10-12, 2001 (in Japanese).

[3] Zaruba, Q. \& Mend, V., Landslides and Their Control, Elsevier Scientific Company: Amsterdam, pp. 84-85, 144-148, 157-161, 1982.

[4] Miyazawa, K. \& Yoshizawa, T., Estimation of three-dimensional slip surface shape using surface displacement survey data of a landslide site. Proceedings of the Society of Civil Engineers, No. 645/III-50, pp. 51-62, 2000.

[5] Boshi, A., Matsumoto, K., et al., A study on slope surface estimation method based on three dimensional displacement measurement results. Japanese Society of Civil Engineer 63th Annual Conference, 2008 (in Japanese), Tohoku University.

[6] Carter, M. \& Bentley, S.P., The geometry of slip surface beneath landslides: predictions from surface measurements. Canadian Geotechnical Journal, 22, pp. 234-238, 1985. DOI: $10.1139 / \mathrm{t} 85-031$. 